\title{
A conceptual cooperative model designed for processes, digitalisation and innovation
}

Daniel Sehlin, Maja Truedsson and Peter Cronemyr

The self-archived postprint version of this journal article is available at Linköping University Institutional Repository (DiVA):

http://urn.kb.se/resolve?urn=urn:nbn:se:liu:diva-163760

N.B.: When citing this work, cite the original publication.

Sehlin, D., Truedsson, M., Cronemyr, P., (2019), A conceptual cooperative model designed for processes, digitalisation and innovation, International Journal of Quality and Service Sciences, 11(4), 504-522. https://doi.org/10.1108/IJQSS-02-2019-0028

Original publication available at:

https://doi.org/10.1108/IJQSS-02-2019-0028

Copyright: Emerald

http://www.emeraldinsight.com/ 


\title{
A Conceptual Cooperative Model Designed for Processes, Digitalisation and Innovation
}

\author{
Daniel Sehlin, Maja Truedsson and Peter Cronemyr \\ Logistics and Quality Management, Linköping University, Sweden \\ daniel.sehlin3@saabgroup.com,maja.truedsson@scania.com, peter.cronemyr@liu.se
}

Daniel Sehlin and Maja Truedsson are M.Sc. students at the Division of Logistics and Quality Management, Linköping University in Sweden. The paper summarizes their M.Sc. thesis.

Peter Cronemyr is an Associate Professor and Senior Lecturer at Logistics and Quality Management, Linköping University, Sweden. He has supervised the thesis work.

\begin{abstract}
Background - Digital transformations are changing society and they force industries to react to the market more frequently. Managers are aware of new technical demands, which increase the pressure of meeting those demands. To meet technical demands, radical innovations are one way to stay competitive. However, it is more complex to make them a part of the business.

Purpose - The purpose of the study was to create a framework for small and medium enterprises to become more efficient by starting digitalise their business processes with the expertise of an external innovation partner.
\end{abstract}

Methodology/Approach - The study was performed at a case company with an abductive approach where both deduction and induction where used to study the empirical findings and formulate new theories in relation to recognised theory. Qualitative methods have been used in the empirical study due to their flexibility and the fact that the focus of the information gathering was to create a context.

Findings - The analysis indicates that a certain level of process maturity can be put in relation to a certain innovation level and a certain level of digital change. According to a process maturity model, an adaptable process could respond to changes in customer demands better, which can be related to changes in the business domain and the society. The research resulted in a Conceptual Cooperative Model based on the three domains of the study. The model has been validated using design reviews with the case company, a consultancy firm and together with an innovation partner.

Practical implications - The model will be a practical template for SMEs to follow when digitalising business processes and how to prioritise them.

Originality/Value of paper - The proposed framework of how to digitalise at different innovation levels coupled to process maturity levels is a novel idea, that could be used for further research.

Keywords - Digitalisation, innovation, process management, business processes, model creation.

Paper type - Research paper. 


\section{Introduction}

\section{Background}

Digital transformations are changing society and they force industries to respond to demand more frequently (Henriette, et al., 2015). Managers are aware of new technical demands, which increase the pressure of meeting those demands (Manso, 2017). Digital economy is continuously changing, and therefore, digital transformation could be described as a realignment of business models, technology and processes that expose new value for employees and customers (Solis, 2014). Stolterman and Fors (2004) describe digital transformation as the changes provided by digital technology affect all aspects of human life. In that sense, digital transformations lead to a world where everything is somehow connected. Organisations have a difficult time to evolve at the same speed as technology and society. Solis (2014) calls this era Digital Darwinism. Furthermore, Kääriäinen, et al. (2017), refer to digitalisation as a fundamental change in society and separate digitalisation from digitising. Digitising means and can be identified as the transformation of analogue data into digital data. To meet technical demands, radical innovations are one way to stay competitive. However, it is more complex to make them a part of the business. (Manso, 2017).

Even with present technical solutions and innovations, companies fail to connect their core processes to new digital business processes.

\section{Problem description}

Innovative ideas and digitalisation have become a strategic tool to continuously develop companies, in a world where the speed of technology increases. Still, it can be difficult to connect innovation and digitalisation progress with core business processes. Hence, there is a conflict between innovation activities and routines in the processes. Routines in daily operations can be related to inflexibility with focus on stability and result in organisational inertness. This is to be compared to innovation, where dynamicity, creativity and flexibility are central (Nilsson, 2015).

There is still no known way to systematically connect different kinds of processes and innovation activities with a well-defined methodology. To access the right technical knowledge can be difficult, especially for SMEs. Hence, there is an opportunity for SMEs to digitalise business processes with the expertise of an external party.

\section{Purpose and research questions}

The purpose of the study was to develop a well-defined framework for small and medium enterprises to use for digital transformation of business processes. This framework should also provide a structure for businesses to understand the possibilities of digitalisation and how/which processes should be prioritised. Furthermore, this framework shall create prerequisites for an external innovation partner to develop digital solutions for business processes.

Figure 1 shows the authors' conceptual framework. Digitalisation is the main topic of the model, innovation is presented by the external innovation partner and the business processes are where improvements are implemented. 


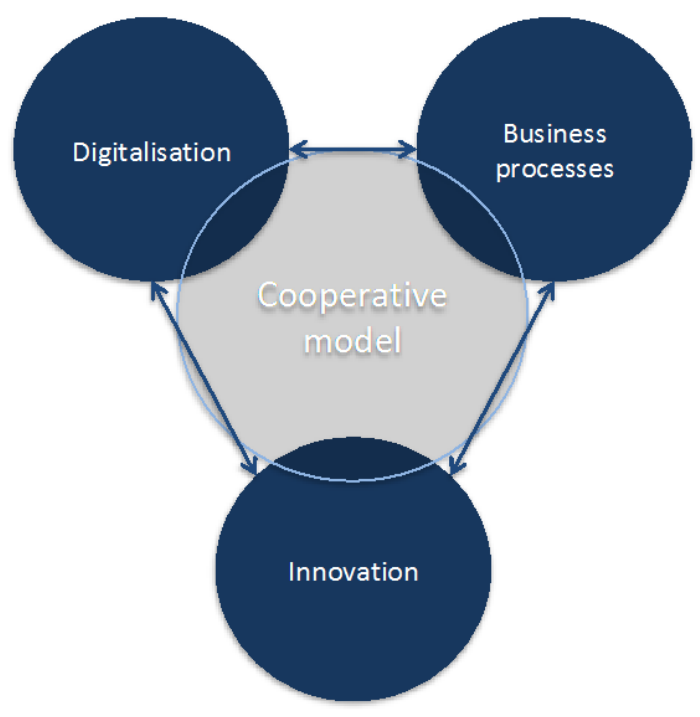

Figure 1: Cooperative model (Conceptual framework)

To develop the framework, the following research questions are used for guidance:

RQ 1: How could opportunities for digitalisation be identified and exploited internally?

RQ 2: How could these opportunities contribute to improvement and development of business processes?

RQ 3: How could the digital opportunities be prioritised and developed with an external innovation partner?

\section{Methodology}

\section{Research design}

The goal of this study was to identify and link the gap between business processes, digitalisation and innovation. The area of the established conceptual cooperative model within the three main areas of digitalisation, innovation and business processes are unexplored in a relation to one another. This study has been done according to an abductive approach. In comparison with deduction and induction, an abductive approach gives ample room for exploration and creativity. Abduction is a procedure of both deduction and induction (Davidson $\&$ Patel, 2011) where researchers study the empirical findings and information to formulate new theories, which means that empirical findings are put in relation to the recognised theory. The chosen procedure is shown in Figure 2. 


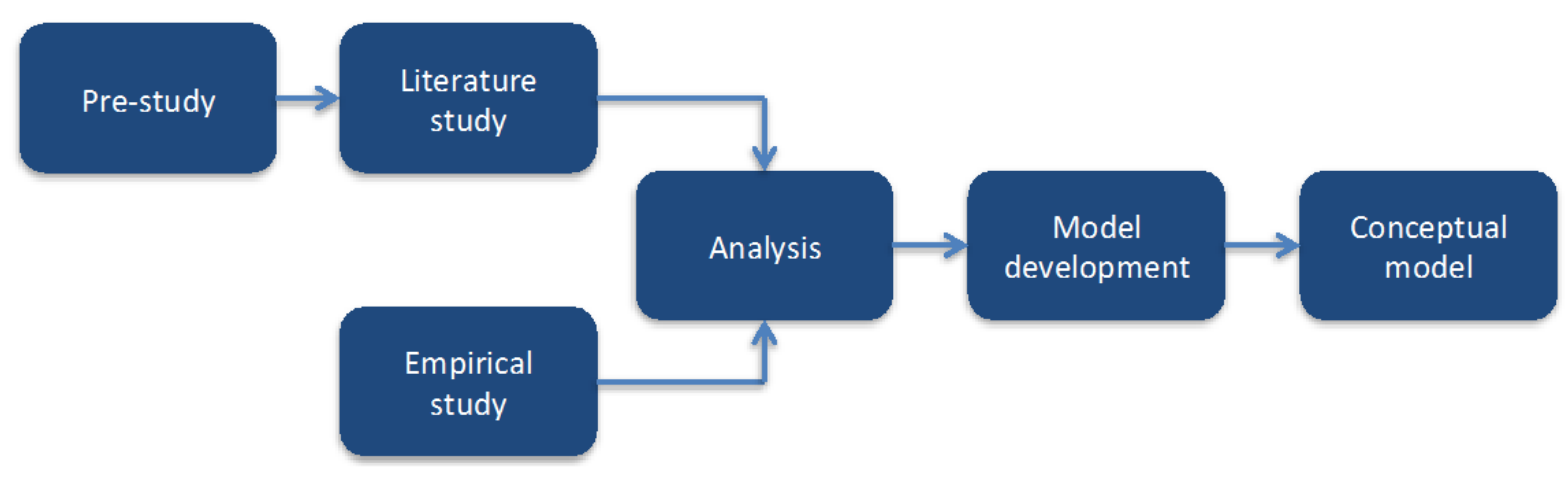

Figure 2: Research design

\section{Pre-study and literature study}

A pre-study was done to understand the scope of the research topics by collecting information regarding the three central areas of this thesis (see Figure 1). Henceforth, business processes will be expressed as process management. Furthermore, requirements of a future conceptual cooperative model were established. The mission was identified and stated according to the required specifications for the conceptual cooperative model. These required specifications were the basis of understanding the necessary and required performance of a conceptual cooperative model.

A deeper research was done into the chosen main areas by the literature study to gather insights and how they can be related to one another. Also, the literature study was the foundation for exploring how digital opportunities can be identified by understanding what kind of digital solutions exists and challenges connected to digitalisation. By studying the area of digitalisation and the challenges of a digital transformation, it is possible to understand how and to which extent digital opportunities can contribute to process management. With this literature study, the authors can answer the first and the second research questions. Approximately around 30 articles including reports and a master thesis have been studied in this research to formulate a common ground for the three main areas in this research, due to the limited number of articles regarding the research scope.

\section{Empirical study and data collection}

Qualitative methods have been used in the empirical study due to their flexibility and the fact that the focus of the information gathering was to create a context (Denscombe, 2007). Together with the literature study, the empirical study was done to answer research questions two and three. The empirical study was analysed based on the literature study in order to generate a start of a conceptual cooperative model.

The focus of this study has been to collect information primarily through interviews and documents conducted at the case company. The interviews were performed in a semi-structured way. The reason why semi-structured interviews have been used was to encourage an open discussion, due to the exploratory approach of this study. 
Table I: Summary of empirical information collections

\begin{tabular}{|l|l|l|l|}
\hline & Time & Present & Purpose \\
\hline Interview 1 & $2 \mathrm{~h}$ & $\begin{array}{l}\text { Consultant, Head of } \\
\text { Development, IT Manager }\end{array}$ & Introduction \\
\hline Interview 2 & $1,5 \mathrm{~h}$ & $\begin{array}{l}\text { Business Developer, IT } \\
\text { Coordinator }\end{array}$ & Digitalisation and innovation \\
\hline Interview 3 & $1 \mathrm{~h}$ & IT Manager & Digitalisation, innovation and processes \\
\hline Interview 4 & $1 \mathrm{~h}$ & Head of Development & Digitalisation, innovation and processes \\
\hline Interview 5 & $1,5 \mathrm{~h}$ & $\begin{array}{l}\text { Technical Specialist, } \\
\text { Strategist, Controller }\end{array}$ & Digitalisation \\
\hline Interview 6 & $1 \mathrm{~h}$ & Consultant & Processes \\
\hline Interview 7 & $1 \mathrm{~h}$ & Business Developer & Processes \\
\hline $\begin{array}{l}\text { Discussion } \\
\text { seminar }\end{array}$ & $1 \mathrm{~h}$ & Consultants & $\begin{array}{l}\text { Open discussion regarding all three } \\
\text { main areas }\end{array}$ \\
\hline Interview 8 & $1 \mathrm{~h}$ & External Innovation Partner & Innovation \\
\hline Interview 9 & $1 \mathrm{~h}$ & Consultant & Processes \\
\hline Interview 10 & $2 \mathrm{~h}$ & Consultant & Processes \\
\hline
\end{tabular}

\section{Analysis and model development}

The analysis of the empirical findings was first summarised by the collected notes, and thereafter, transcriptions were carefully performed. Keywords from the interviews regarding the three main areas were collected. The output of the analysis of findings resulted in important factors and sequential steps that were included in the conceptual cooperative model.

In this study, previous models within digital transformation, product development processes and a previous master thesis regarding welfare technologies were used as inspiration and a basis for developing a conceptual cooperative model. These existing models helped the authors find the main areas when creating the core process for the conceptual cooperative model.

\section{Frame of reference}

\section{Digitalisation}

The new era of Industry 4.0 (Bortolini, et al., 2017; Atzori, et al., 2010) and digitalisation have changed the way we usually operate and has created new technologies and innovations to meet present and future demands (Kääriäinen, et al., 2017). Bossen and Ingemansson (2016) discuss digital technologies in the Swedish manufacturing industry and explain areas of digitalisation and solutions for specific areas. The specific areas are data, automation, digital interface and connectivity. Hence, the solutions can be grouped by common fundamental digital technologies. These areas and solutions are presented in Table II. 
Table II: Areas of digitalisation, interpretation of (Bossen \& Ingemansson, 2016)

\begin{tabular}{|c|c|c|c|}
\hline \multicolumn{4}{|c|}{ Digitalisation } \\
\hline Data & Automation & Digital interface & Connectivity \\
\hline $\begin{array}{l}\text { Simulation and } \\
\text { modelling } \\
\text { System of systems } \\
\text { Big data analysis }\end{array}$ & $\begin{array}{l}\text { Additive } \\
\text { manufacturing } \\
\text { Smart electronic } \\
\text { systems }\end{array}$ & $\begin{array}{l}\text { Social networks } \\
\text { Machine-Human } \\
\text { Visualisation }\end{array}$ & $\begin{array}{l}\text { Cyber security } \\
\text { Wireless } \\
\text { communication }\end{array}$ \\
\hline \multicolumn{4}{|c|}{ Digital solutions } \\
\hline $\begin{array}{l}\text { Predictable } \\
\text { maintenance } \\
\text { Smart products } \\
\text { Decisions programs } \\
\text { Self- diagnostic } \\
\text { Adaptive steering }\end{array}$ & $\begin{array}{l}\text { Recognition } \\
\text { equipment } \\
\text { Autonomous } \\
\text { systems } \\
\text { Collaborating robots } \\
\text { Combination of } \\
\text { machines } \\
\text { Flexible production } \\
\text { systems }\end{array}$ & $\begin{array}{l}\text { Fourth party } \\
\text { logistics } \\
\text { Customized } \\
\text { manufacturing } \\
\text { E- commerce } \\
\text { Adaption of } \\
\text { communication } \\
\text { Performance-based } \\
\text { contracts }\end{array}$ & $\begin{array}{l}\text { Integration of robots } \\
\text { Remote-controlled } \\
\text { maintenance } \\
\text { Enhanced reality } \\
\text { Digital services } \\
\text { Monitoring } \\
\text { processes } \\
\text { Integration of } \\
\text { factories }\end{array}$ \\
\hline
\end{tabular}

Introducing digital strategies or solutions is equal to comprehensive changes for many enterprises (Jacobi \& Brenner, 2017; Solis, 2014). Digitalisation makes businesses act rapidly in a short time frame where there is a need for modifying entire strategies and cultures. Digital change starts with top management and digital leadership (Jacobi \& Brenner, 2017). Kane, et al., (2015) also argue that digital leaders compared to other leaders need a defined digital strategy. The digital strategy is a key ingredient by combining culture and leadership toward a digital transformation.

Thus, even with guidelines for the formulation of digital strategies and key successful aspects of digital transformation, there is still a missing connection in how to make digital transformation work in practise. Obstacles are not the only technology itself, but issues such as the human factor, organisational cultures, resistance to change, lack of knowledge, lack of resources, motivation and risk-taking (Schwertner, 2017).

Digital transformation is a change that affects organisational levels in different ways, see Table III.

Table III: Levels of digital transformation (Kääriäinen, et al., 2017)

\begin{tabular}{|l|l|}
\hline Levels & Digital changes \\
\hline Process & $\begin{array}{l}\text { Adopting new digital tools and streamlining processes by reducing } \\
\text { manual steps }\end{array}$ \\
\hline Organisation & $\begin{array}{l}\text { Offering new services and discarding obsolete practises and offering } \\
\text { existing services in new ways }\end{array}$ \\
\hline Business domain & Changing roles and value chains in ecosystems \\
\hline Society level & $\begin{array}{l}\text { Changing society structures (type of work, means of influencing } \\
\text { decision making) }\end{array}$ \\
\hline
\end{tabular}


There are companies that provide other businesses with expertise and knowledge toward a digital transformation. Digitalisation of business processes is not an entirely new phenomenon. Still, it can be difficult for SMEs to know where to start when digital knowledge is absent internally. To better meet challenges of digitalisation, Kääriäinen, et al., (2017) have developed a conceptual framework to better benefit from digitalisation in practise. Their framework is supposed to be a support tool for digital transformation. It is divided into four sequential steps:

1. Positioning a company in digitalisation

2. Review current state

3. Roadmap for digitalisation

4. Implementation with technical support

Their framework focuses on digital transformation in companies and follows a plan-do-studyact principle that is commonly known for improvements. It describes an approach to benefit from digitalisation in practise. Still, the framework can be considered to be too general and does not include prioritisation of processes. It is mentioned in their conceptual model, that an analysis should be done to consider which processes have the highest potential of digitalisation. How this analysis and the prioritisation are done is not fully explained.

\section{Innovation}

Innovation is not only creating new products. It includes an understanding of the customer demands and how to deliver those demands in new ways and in new collaborations with other businesses (Keeley, 2013). Innovation is also associated with 'newness' (Varis \& Littunen, 2010) and can be considered be equal to new ways of doing business, new services and systems (Keeley, 2013). Gupta, et al., (2007) define innovation as a development or production of a new idea. Even with the association with something new or inventions, there is no simple way to clearly define the term innovation, due to shape or degree. Innovation can also be distinguished between product innovations, process innovation, organisational innovation and market innovation (Varis \& Littunen, 2010). It can also generate new engagement and interactions between customers and organisations. New innovations can create feasible and practical tools or contributions (Gupta, et al., 2007). Hence, the challenges are to transform innovations opportunities that can generate organisational growth (Keeley, 2013; Francis \& Bessant, 2005).

Creative work including technical innovations, need to be taken care of and implemented in core business processes. Moreover, innovation, such as digital innovation is more common and higher prioritised than initiatives from quality management. Still, digital innovation relies on having a process structure, clear responsibilities and quality management methods for measuring effectiveness and efficiency (Rönnbäck \& Eriksson, 2012). Clausing (1994) has described and explained a course of actions for a dedicated technology development to collect optimal technical concepts from a creative environment. The first step involving technology strategy is a guideline for the creative work and include technologies that are most needed in a development of new products. The second step, creative work is an important step where new ideas are generated and room for inventions are made. This step can be divided into three substeps: Definition of needs, Invention and Concept selection. The best concepts with the desired robustness are then selected and transferred to the concept phase and a start of a new product can begin. The technology development process for product development is shown in Figure 2. 


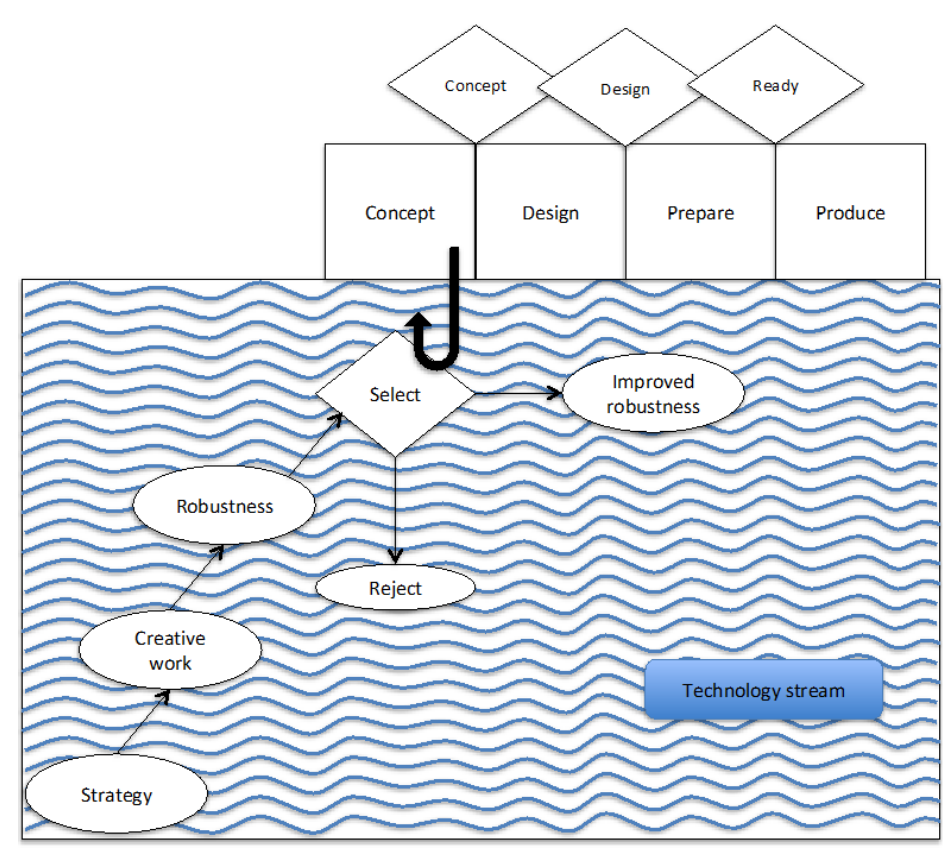

Figure 2: Technology development in the Technology stream (Clausing, 1994)

The step between strategy and creative work in the schedule of developing robust technological solutions can be considered to be quite broad and weak, i.e. how the creative work by technical specialists should be aligned to the direction of the strategy. However, this step has been further evaluated by Cronemyr (2000). He describes how a sub-process to Clausing's Technology Stream, called Phantom Turbine Development, was developed in 1998 at Swedish gas turbine development company ABB STAL (today a part of Siemens). The main purpose of Phantom Turbine Development was to focus on future customer demands in R\&D. It was necessary to have a relation to a 'real' product to make a well-defined goal for the technical specialists and the R\&D engineers. Within the Phantom Turbine Development, the main goal was to make it possible to produce the so-called Phantom Turbine at the right time in the future. Even though the Phantom Turbine would never be produced, future products would meet future customer needs. (Cronemyr, 2000).

\section{Process Management}

To create value and integrate value-added activities in organisations are central actions in process management. Process management has gained popularity in many businesses such as service companies and within the public sector (Hellström, 2006). Value is what is considered to be important for the customer (Clausing, 1994). A process is, according to Rentzhog (1998) as well as to Bergman and Klefsjö (2012), a set of activities that repeats and creates value for a customer.

A company can be described as a network of processes. The processes can be divided into different type of processes, main (core/business) processes, support processes, and management processes. The main processes' purpose is to fulfil the external customers' requirements and expectations. Furthermore, product development processes should create value for future customers' while production and distribution processes should create value for current customers. Support processes have internal customers, such as recruitment processes, and different types of administration processes. Management processes' purpose is to decide about goals and strategies of the organisation. At the same time, the management processes should support improvements for the other processes. The purpose of each process is to satisfy customers with the minimum amount of resources as possible. Different kinds of resources are required in processes, resources as information, energy and working hours. (Bergman \& Klefsjö, 2012) 
According to Beer and Nohria (2000), change initiatives of restructuring, downsizing or new technologies fail up to $70 \%$ of the times. They state the reason for those failures is due to managers' urgency to change the organisation. Digital strategies and digital solutions can be equal to change for many businesses. To better meet change initiatives and improve insight into process management, Cronemyr and Danielsson (2013) developed a process maturity model to better develop and improve process management, see Figure 3.

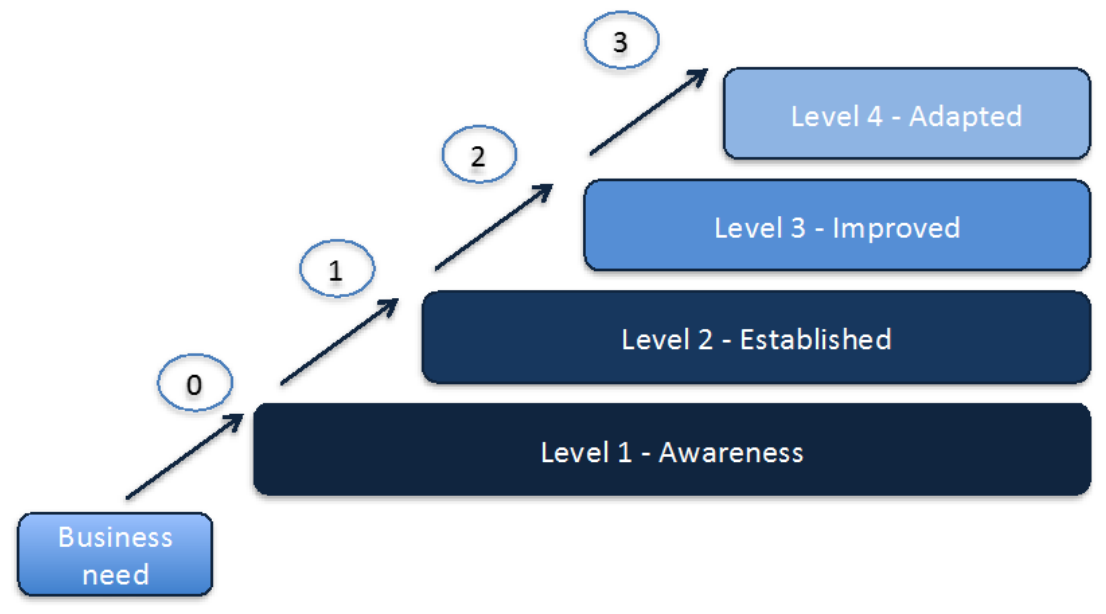

Figure 3: The process maturity model (Cronemyr \& Danielsson, 2013)

The model consists of one level of business need, which is a pre-level step, and four maturity levels.

The first level of maturity is the level of awareness. Top management are aware of process management and the usefulness of it. This awareness is essential to establish processes. At this level, some influence of process management can be found. (Cronemyr \& Danielsson, 2013)

At the next level, processes are established in the organisation. The processes are put in practise and documented containing necessary constituents. At this level, it is necessary to have some demands delivered from the process and attention from the management for the process to be sustainable. (ibid.)

At level three, the improved level, process data are the focus. To improve the processes, they need to be fully established. Improvements are better implemented with a stable basis. The foundation of improvements should be based on facts, where structured methods and customer focused measurements are considered to be necessary. Controls for the processes should also be added and established when measuring results. (ibid.)

The top level of process maturity is the adaptable level. At this level, the processes need to be more proactive and flexible together with a closer collaboration with the customer. Reaction to changes in the process are detected earlier by using statistical process control. Processes at this level are more able to adjust to changes of customer demands. For this level, there is a need for everyone working with and in the processes to have a fundamental understanding and commitment for the process. (ibid.)

\section{A comparison between the maturity of quality management and digital innovation}

Quality management and digital innovation are most commonly separated departments, not only in organisations, but also in the academia. Moreover, knowledge from each section is kept accordingly and knowledge sharing is therefore limited (Rönnbäck \& Eriksson, 2012). Rönnbäck and Eriksson (2012) compared quality management and digital innovation with a 
spectrum of principles. Their research showed that having a well-defined process perspective is essential for digital innovation. Focusing on processes will have a positive effect on digital innovation. Using quality management strategies and tools can improve considered poor digital innovation principles. Having cross-oriented teams of IT specialists and quality management in a process-oriented organisation, can have a positive effect on both departments and in the end, the whole organisation.

\section{Results from Empirical study}

\section{Description of the case company}

The case company where the study was conducted is a public utility within the real estate market that develops, builds and maintains public buildings such as schools, libraries and sports arenas. They have a responsibility and a mission from the municipality. It is a small company with around 70 employees. The company was selected as case company by the consultancy firm, requesting this study.

\section{Digitalisation at the case company}

According to the case company, $20 \%$ of their buildings, foremost bigger buildings are connected. Minor buildings are not connected to the same extent due to costs. Still, new constructions and new buildings are digitised to a greater extent. Digital solutions in buildings are related to ventilation, heat and cold calibrations and maintenance. The starting point of connecting buildings was to detect errors before the customer did and to meet new energy requirements.

Within their processes, several systems are used. Recently, a digital platform has been implemented in the organisation where they work with digitising on a daily basis. It was stated that they separate digitalising from digitising.

\section{"What we do today is digitising. We improve to make things faster and more reliable".}

Different systems are used in their business processes to collect and secure information and data. One challenge for the company is to make all employees use the existing systems that are integrated into the processes. Everyone does not optimally use the systems. Another challenge is to find the right competencies and to have the leadership to motivate and to make the progress move forward. Therefore, the company see the opportunity to work with an external partner that can deliver new innovative ideas.

A digital strategy has been developed with an initiative from the development manager and the IT manager. The strategy is not communicated and not established yet and there is a need for elaborating the strategy into text. Also, the strategy is not fully integrated at the top management level.

\section{Innovation at the case company}

Together with process development, there has been a start of structure the work of concept improvements. The PDSA cycle is a common tool to continuously work with improvements and change within the business. When identifying improvements and necessary change with a bigger scope that requires more resources and are related to a higher level of business development, a business development portfolio is used. This portfolio identifies what the business should deliver in relation to goals and business development according to a structured work procedure. 
"There is an interface between improvements, innovation and development with different conceptions. Innovation for me is to think new and to think outside the box and in that way, find the shortcut without losing quality".

Innovation for the case company is related to improvements and thinking outside their way of working. For example, how they can think more innovative to meet business needs. Also, there is a responsibility for the dialogue with customers and suppliers. Innovation regarding changing the whole business has not been the primary focus.

During one interview, it was explained that innovation at the case company is divided into three different steps according to Figure 4, where the bottom circle is related to core offerings, estimated to represent $70 \%$ of innovation initiatives, the middle, estimated to $20 \%$, and the top, with $10 \%$. In the bottom, core is related to enhancement to core offerings in the organisation. The middle section is related to pursuit of adjacent opportunities. The top the circles presents the perspective of ventures into transformational territory. Currently, the case company work first and foremost in the bottom circle and in the middle circle but intent to work with an innovation team to work toward the top of the circles.

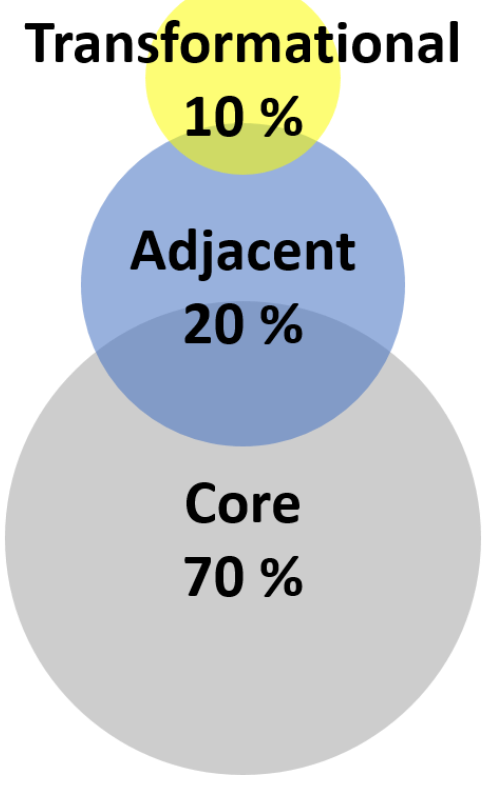

Figure 4: Allocation of resources on different types of innovation (Nagji \& Tuff, 2012)

Recently, an innovation incubator also called the 'innovation lab' was started. The purpose of the innovation incubator is to make space for innovative initiatives and other suggestions of future improvements. Anyone within the company is welcome to participate in cases in the innovation lab.

\section{Process Management at the case company}

A collaboration to develop their processes was made with the consultancy firm one and a half year ago to develop their processes further. It is a procedure to create an entirety by building up the processes including information systems and where the same concepts are used. Fifteen processes are visualized, three management processes, five core processes and seven support processes. All processes are not fully completed and structured. Every process has a process owner, a process team and a process leader. There is a communicated plan which processes are the next to start developing. Processes are built and visualised by workshops including a brainstorming session where the process team is created with a designated process owner and a process leader. Requirements and important activities to deliver the compulsory output for 
the processes are settled together with which information is needed to deliver the required output. Process development is led similarly to projects. Tests are performed to make sure the system and the process deliver the settled requirements.

"When writing down a process, the challenge is not to make it complex, it is to make it simple".

The processes are continuously improved by suggestions from the people working in the processes. The suggestions of improvement related to a certain problem are described and documented in an 'improvement box' in the digital platform. When improvements are done in the digital platform, the suggestions are sent to the process owner and he or she is responsible for evaluating suggestions of improvements. It is stated that there is a need for a system to take care of suggestions from the processes. The current solution by communicating suggestions by the digital platform is considered to be a temporary solution, which will be continuously improved. When effective processes are visualised and developed, they can be developed further when the whole picture of processes is done. At that state, digital opportunities can be considered as a vitality to continuously improve processes.

"Right now, we do not have a mutual picture of what we do and what we deliver in the different processes. It is not until we have the whole picture that we can find even smarter solutions for the company at a comprehensive level".

\section{Description of the innovation partner}

The external innovation partner is a company that helps companies to become business organised in order to meet the connected world. They deliver suitable solutions with technical expertise to power innovations. They are a strategic advisor partner and work with innovation, the creation of innovations, testing and management of digital solutions. Their fields of specialisation are within digitalisation, Internet of Things (IoT), Cloud Services and Secure Connectivity.

There are several challenges related to digitalisation according to the innovation partner. International competitors in Asia are going to challenge the Western world. In some firms, the right competence can be difficult to find internally. Furthermore, there are cultural aspects to take in consideration and can be a challenge in the digital world. Digitalisation is considered to be a high priority for many companies.

When the innovation partner working with business transformation, there is a certain procedure that is performed. Firstly, an understanding of the customer and customers' needs and problems are identified. This is done by inspiration workshops. Continuously, understanding of new business models and wanted operating models are done. Innovative ideas and suggestions are presented to their customers together with proof of concepts. This procedure has different time horizons depending on the maturity of the customer and problem areas. They strive to be near the customer during collaborative projects by having frequent follow-ups.

\section{Analysis and conceptual cooperative model}

\section{Digitalisation}

There is a conflict between processes with structured routines and innovation which requires flexibility and creativity. In that sense, flexibility and creativity can have limited capacity when it comes to structured processes. Still, to continuously improve the processes, innovative ideas can be required. This agrees with the challenges of the case company. The case company is a small enterprise with limited resources and digital competence, and therefore, the need external expertise to start digitalising their business processes is necessary. According to theory, obstacles towards a digital transformation could be related to the human perspective of resistance to change, organisational cultures, lack of knowledge, lack of resources, motivation 
and lack of risk-taking. Some of those obstacles have been stated in the empirical findings. Some employees understand the situation and are motivated to meet the digital challenges, while others do not have the same engagement. It was indicated during the interviews that one of the major challenges was the human standpoint. Several respondents agree that there is a lack of resources and knowledge within the area of digitalisation. Therefore, it can be necessary to use external partners to exchange knowledge and to digitalise the business. Furthermore, one more challenge present at the case company is to make all employees use the existing data systems that are integrated into the processes. The full potential of the functions of the systems is not used optimally. It could be plenty of reasons why the employees are not using the full potential of the systems. It might be because they do not have the correct competence, have not received the knowledge of the whole system or it could be related to organisational culture, employees do what they always have done.

Today, the case company are mostly working with digitising by transforming analogue data to digital data. This can be related to an early stage of embracing digital opportunities. Moreover, the digital solutions of sensors etc. related to their buildings, are used to be able to satisfy the customers using the buildings. These digital solutions can be understood as front-end solutions. Therefore, opportunities regarding an end to end solutions are not fully explored.

\section{Innovation}

The case company works with innovations according to allocation of resources on different types of innovation, where they focus on core offerings and pursuit of adjacent opportunities, see Figure 4. Based on the interviews, innovations were viewed differently. One possible reason could be of the broad definition of innovation which can differ depending on branch or company. Furthermore, innovations in this paper can be related to digital innovations, where an innovation partner is the source of expertise of digital innovations. When discussing innovation during the interviews, innovation for the case company was to improve what exists in the processes. For the case company, it is more about what is new to them, they do not need to be revolutionary and invent something totally new. The case company is working with the bottom and the middle level of the innovation circles, core offerings and pursuit of adjacent opportunities, to develop the business in a bigger scope. It can be related to when starting a larger project including more resources in terms of money, working force, time and competence. While the top of the circles, ventures into transformational territory, is something the case company work towards with the initiative of the 'innovation lab'. This could be analysed and compared to the different levels of digital changes, according to Kääriäinen, et al. (2017). Digital transformation in different levels can be on how innovative initiatives are different levels of digital changes transformation and the innovation circles are related to innovations. Comparison between levels of digital change and allocation of resources on different types of innovation is visualised in Figure 5. 


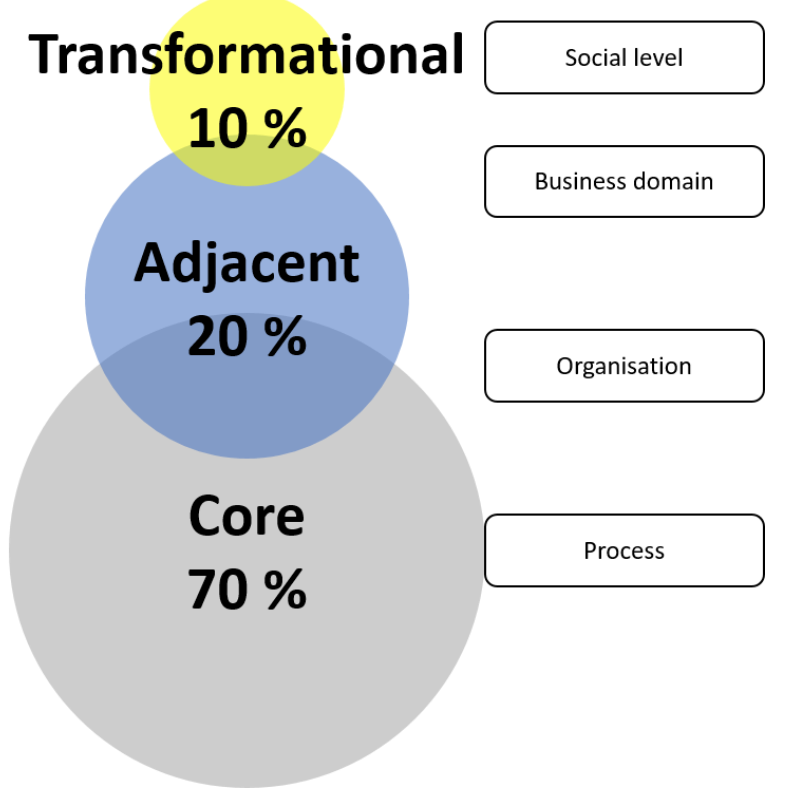

Figure 5: The comparison between levels of digital change and allocation of resources on different types of innovation.

The allocation of resources on different types of innovation can also be related to Kääriäinen, et al. (2017) explanation of how impacts of digitalisation can be viewed. The impacts of digitalisation are viewed from three different extents, internal efficiency, external opportunities and disruptive change. This is shown in Figure 6.

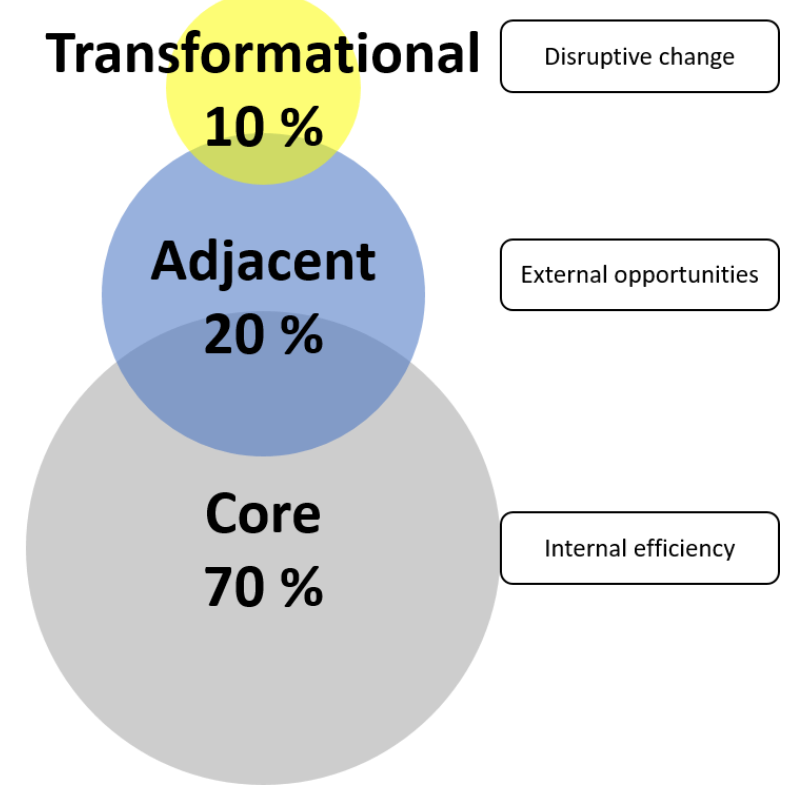

Figure 6: Comparison between digital impacts and allocation of resources on different types of innovation.

In this specific case, the case company is municipally owned. That can affect which kind of business relations are appropriate or not. Their initiative with the innovation lab indicates that the company want to take care of internal forces and ideas which can be considered to be a good alternative to motivate co-workers to be creative and think outside the company box or their individual box. It also indicates that the company meet future challenges in an innovative way. 


\section{Process Management}

The company's processes are continuously developing. With not fully visualised processes, there can be a risk of not following the conceivable processes. Established processes can be a key to work with continuous improvements, which also was indicated in the empirical study. By having a settled way of working, suggestions of improvements can easier be taken care of. In several interviews, process maturity was discussed when discussing the digital transformation of processes. Most of the interviews stated that it can be required to have a certain process maturity to better meet digital opportunities. Digital transformation is a major change for many businesses, which was indicated by the case company as well. In small and medium enterprises, it can be preferable to have a level of awareness to better meet and handle digital opportunities. As mentioned by Beer and Nohria (2000), 70\% of change initiatives fail. Change initiatives can also be related to digital change. Therefore, it is considered that small and medium enterprises can integrate digital solution more efficient if some of their business processes have a higher level of maturity according to the process maturity model by Cronemyr and Danielsson (2013). Then, digital integrated solutions can be compared to a current state, if the state of processes is considered to be stable.

Moreover, if the process maturity and levels of digital changes are put on two axes, the case company is positioned in the lower left corner. According to the empirical findings, the process maturity is at an early stage and therefore, digital changes or innovations are related to core offerings. With a high maturity of processes, higher steps can be reached in the innovation circles but also in levels of digital change. This indication is visualised in the marked area in Figure 7. According to the maturity model, a process of an adapted level can respond to changes in customer demands better, which can be related to changes in the business domain and the society. Still, this does not necessarily mean that ventures into transformational territory cannot be implemented or delivered if processes have a lower maturity level. It is just indicated that digital opportunities located in a higher level of digital change, can be met more efficient if the processes have a higher degree of maturity. The relation between process maturity, levels of digital change together with the three areas regarding innovations according to the case company, is visualised in Figure 7.

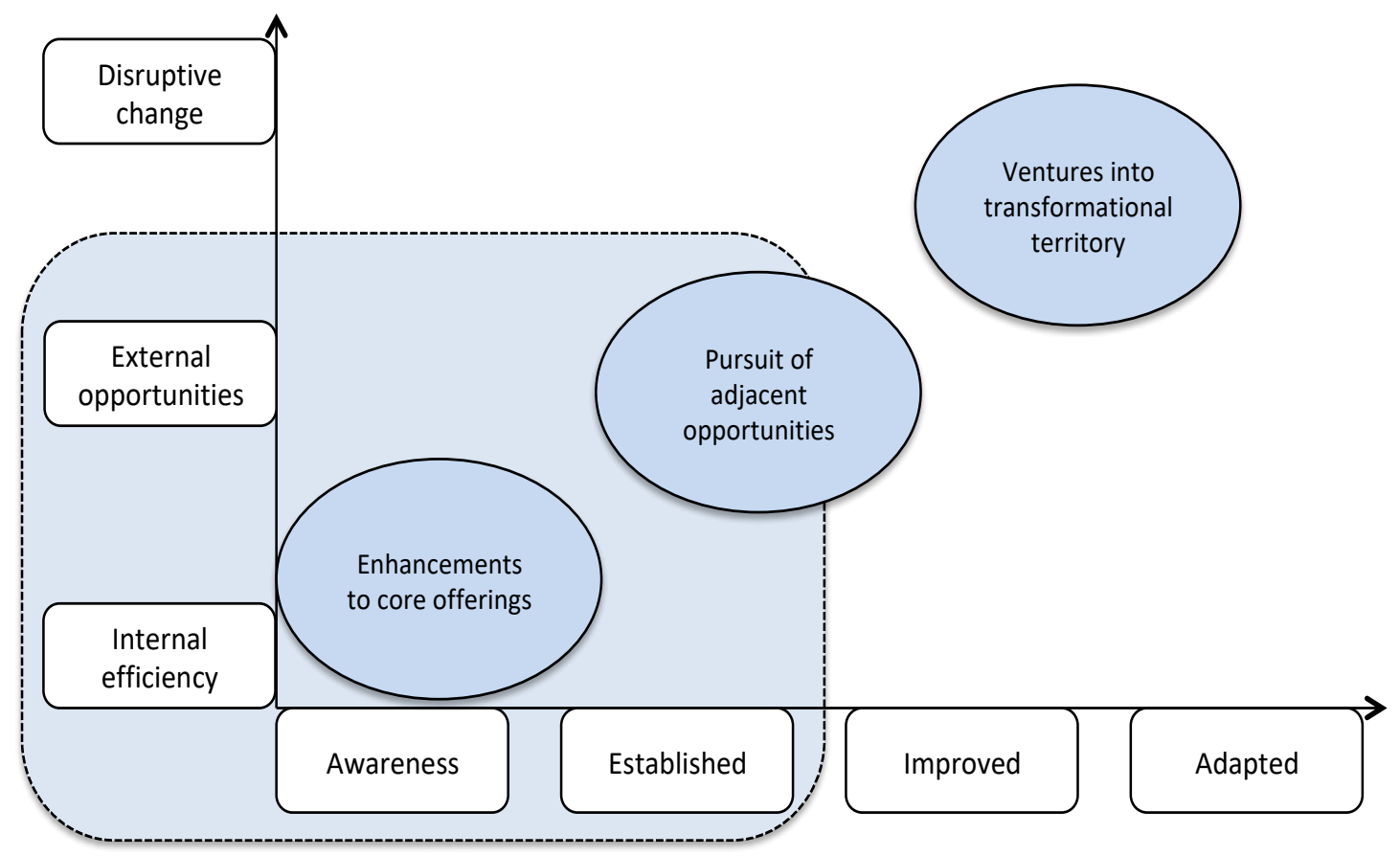


Figure 7: A relation between process maturity, levels of digital change together with the three areas regarding innovations.

\section{A Conceptual Cooperative Model Designed for Processes, Digitalisation and Innovation}

By analysis of empirical findings and the literature study, a Conceptual Cooperative Model Designed for Processes, Digitalisation and Innovation has been developed, see Figure 8. This model should support strategies towards a digital transformation. Therefore, a strategy that supports digital transformation is a prerequisite in this case. This model also requires organisations working accordingly to Process Management.

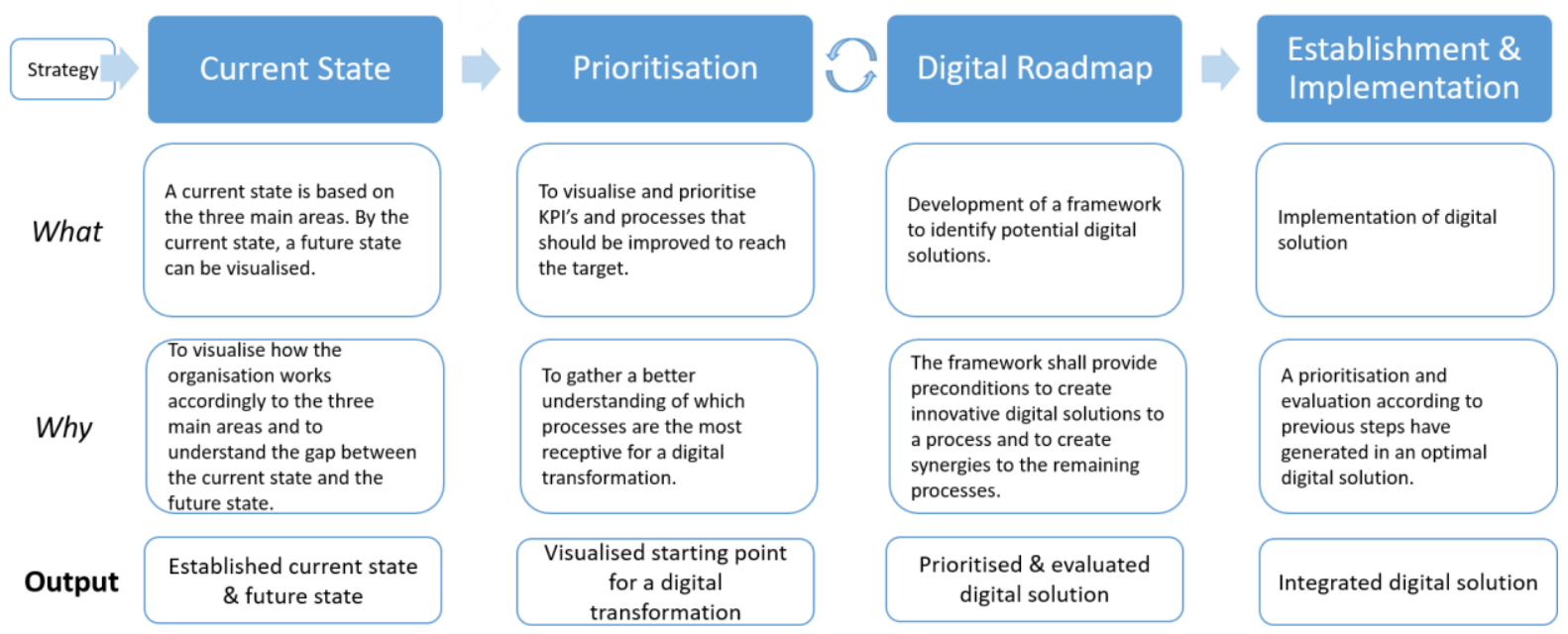

Figure 8: A Conceptual Cooperative Model Designed for Processes, Digitalisation and Innovation

The purpose of the first step in the model, the Current State, is to evaluate how an organisation currently work within the three main areas of digitalisation, processes and innovation. By an established current state, a future state can be visualised. This is done with cooperation in all the three main areas. The gap between the current state and the future state could be understood by performing a SWOT-analysis. Methodology regarding process maturity is also performed in this step. The current state intends to inspire organisations to become digital. Inspiration workshops regarding digitalisation can be conducted, tentatively by an innovation partner. The output of this step results in an established current state and a visualised future state.

In the following step, Prioritisation, a first prioritisation is performed. The second step intends to gather a better understanding where to start a digital transformation. This is done to reassure that a digital transformation starts accordingly to the current state and the future state by prioritising KPIs and processes with specific criteria. A reason to include the connection of KPIs was to evaluate a possible implementation by studying how the certain KPI or KPIs were improved by a possible implementation. Therefore, KPIs need to be visualised. Thereafter, KPIs are prioritised by the importance of changing or to meet the future state and the strategic goals. Subsequently, selected KPI or KPIs are connected to relative internal processes. When the connection between KPIs and processes is visualised, processes are prioritised by certain criteria. This can be performed by a Quality Function Deployment. One of the criteria concerning process maturity. Moreover, this is considered to be essential from a process perspective. When implementing digital solutions, an implementation can be related to change initiatives. It is indicated by the analysis, by having a certain level of process maturity, innovative digital solutions are viewed in a certain perspective. Therefore, prioritisation of 
processes according to process maturity is included in this step. The output of this step results in a starting point for a digital transformation according to a prioritised process based on certain KPIs and according to process maturity.

In the third step, the Digital Roadmap includes the path towards potential digital solutions. The purpose of this step is to find optimal digital solutions to a prioritised process. Firstly, factors which have an influence on the process should be identified. An identification of factors can be done in several ways (root cause diagram, brainstorming etc.). Furthermore, the purpose of an identification of factors is to indicate which type of areas can be related to the problems. Henceforth, when factors are identified and possible problem areas are visualised and communicated, it will thereby be easier for an innovation partner to provide suggestions for digital solutions to improve the process. The innovation partner will develop the digital solutions together with the expertise of the process. An evaluation of the digital solutions should be done with a risk analysis (FMEA) and a prioritisation of the digital solutions (prioritisation matrix, Pugh matrix or QFD). The final step in the digital roadmap is to analyse if the chosen digital solution could be used in other processes as well and it could be done in several ways (root cause diagram, brainstorming etc.). This is a structured way to find the correct processes and digital solutions.

The last step in the conceptual cooperative model involves the establishment and implementation of selected digital solution or solutions. To establish digital solutions, a proof of concepts can be performed. If the proof of concepts is successful, the digital solution would be implemented and integrated fully. To monitor the implementation, KPIs related to the process are observed and measured. In this research, there is a delimitation of this step and will not be further developed.

The model has been validated using design reviews at the case company, consultancy firm and together with the innovation partner.

\section{Conclusions}

\section{RQ1. How could opportunities for digitalisation be identified and exploited internally?}

The answer to the first research question can be answered differently, depending on the branch of the company and organisational aspects. Firstly, it can be preferable to get an understanding of the scope of digitalisation. In a present era of Industry 4.0, digitalisation includes a broad scope of digital opportunities in relation to data, automation, digital interface and connectivity. Furthermore, to connect the existing digitalisation areas with the organisation may be necessary in order to find digital opportunities most suitable for the process. Furthermore, opportunities could also be identified with a constant dialogue with the customer to meet customer requirements and their future requirements. By work accordingly, to process management within organisations, it is a considerable an important course of action to find opportunities internally, in this case, digital opportunities. If companies apprehend the importance of process management, organisations can improve continuously by utilising digital opportunities with a basis in process management. According to the theory, a digital strategy, digital vision, leadership concerning digital encouragement and an open organisational culture are aspects that could increase the possibility to find opportunities towards a digital transformation. Otherwise, small and medium enterprises can consider a partnership with an external innovation partner in order to find opportunities for digitalisation due to their external expertise in the area of digitalisation. 
How opportunities can contribute to process management can be difficult to determine due to how well the settled prerequisites for a digital transformation are established. However, different levels of digital innovations can contribute to processes depending on processes maturity level. According to the empirical findings, the process maturity can contribute to process management in terms of how receptive a process is and how receptive involved stakeholders are. It has been indicated that if processes have a maturity level of Awareness, digital solutions are related to core offerings or digitising. Therefore, in a process level of Awareness, digital solutions contribute to process management by improving the current state of how the process is currently operated. It is indicated but not fully determined that a higher level of process maturity, digital innovations and opportunities can possibly be related to pursuit of adjacent opportunities in terms of creating new value to customers. By creating new value to the customers, also means a change in the processes. Henceforth, it is essential to have a digital perspective if the new value is created when changing the associated processes. Otherwise, there is a risk of a front-end focus when only finding new ways of creating new value to the customer. Also, by having a higher level of process, there is an estimation and understanding of customer changes of demands can be met proactively in a higher level of process maturity.

\section{RQ3. How could the digital opportunities be prioritised and developed with an external innovation partner?}

First and foremost, to better meet and prioritise possible digital opportunities, there is a need for a structured course of actions that can be observed in the conceptual cooperative model. Opportunities can first be prioritised after a prioritisation of KPIs and a prioritisation process maturity based on step two in the conceptual cooperative model, to make sure digital opportunities are related to organisational strategies. This is also done to define applicability and significance of digital opportunities. Based on step two in the conceptual cooperative model, an evaluation according to a simplified QFD can be performed where KPIs and their connections to processes are visualised. The starting point towards a digital transformation can be prioritised according to certain criteria. In the conceptual cooperative model, the criteria are related to process maturity, independence of process and capability to change. By grading the importance of criteria, processes perceive a prioritising value based on those criteria to better visualise the entirety of processes shown in the QFD.

By having a starting point of which process to start to digitalise, factors influence the processes are identified. KPIs, KPDs are examples of factors or other factors that may influence processes and can be detected by a root cause diagram or brainstorming. The output of identifying factors and what influences those factors discharge in a framework for an innovation partner to develop digital opportunities based on a structured approach taken in previous steps performed in the conceptual cooperative model. Suggestions of digital solutions from an innovation partner should be evaluated and further developed with accurate knowledge from the process. Knowledge of the process can be related to employees who have expertise regarding activities in the process. Suggestions of digital solutions can be prioritised according to a prioritisation matrix, a Pugh matrix or the previous performed QFD in step two of the conceptual cooperative model. To summarise, digital opportunities are therefore prioritised based on a structured course of actions where KPIs and processes are firstly prioritised according to settled criteria. Subsequently, digital opportunities can be prioritised based on evaluations made by accurate expertise from the process and additionally with methodologies from different prioritisation tools such as prioritisation matrix, Pugh matrix and QFD. 


\section{Acknowledgements}

This article has resulted in many insights regarding challenges of digitalisation and how to integrate innovative digital solutions into core business processes in a suitable way. The methodology from the Conceptual Cooperative Model Designed for Processes, Digitalisation and Innovation, is one step of a structured approach towards a digital transformation. A great thanks to the case company and to the innovation partner for their openness and for their appreciated collaboration in this work, and considerably great acknowledgements to Propia for their expertise and opinions. They made this research possible to complete. 


\section{References}

Atzori, L., Iera, A. \& Morabito, G., 2010. The internet of things: A survey. Computer networks, 54(15), pp. 2787-2805.

Beer, M. \& Nohria, N., 2000. Cracking the code of change. Harvard Business Review, 78(3), pp. 133-141.

Bergman, B. \& Klefsjö, B., 2012. Kvalitet - från behov till användning. 5 ed. Lund: Studentlitteratur AB.

Bortolini, M. et al., 2017. Assembly system design in the Industry 4.0 era: a general framework. FAC Papersonline, pp. 5700-5705.

Bossen, H. \& Ingemansson, J., 2016. Digitalisering av Svensk Industri - Kartläggning av svenska styrkor och utmaningar, Stockholm: Roland Berger AB.

Clausing, D., 1994. Total Quality Development : A Step-By-Step Guide To World-Class Concurrent Engineering. 1 ed. New York: ASME Press.

Cronemyr, P., 2000: Towards a learning organization for product development. Licentiate thesis, Division of Quality Technology and Management, Linköping University.

Cronemyr, P. \& Danielsson, M., 2013. Process Management 1-2-3 - a maturity model and diagntostics tool. Total Quality Management \& Business Excellence, June, 24(7-8), pp. 933944.

Davidson, B. \& Patel, R., 2011. Forskningsmetodikens grunder - Att planera, genomföra och rapportera en undersökning. 4 ed. Lund: Studentlitteratur AB.

Denscombe, M., 2007. The good research guide for small-scale social research projects. 3rd edition ed. Berkshire: Open University Press McGraw-Hill.

Eriksson, H. \& Rönnbäck, Å., 2012. A case study on quality management and digital innovation: Relationship and learning aspects. International Journal of Quality and Service Sciences, (4), p. 408

Francis, D. \& Bessant, J., 2005. Targeting innovation and implications for capability development. Technovation, 25(3), pp. 171-183.

Gupta, A. K., Tesluk, P. E. \& Taylor, S. M., 2007. Innovation At and Across Multiple Levels of Analysis. Organization Science, November-December, pp. 885-897.

Hellström, A., 2006. CONCEPTIONS OF PROCESS MANAGEMENT - AN ANALYSIS OF THE DISCOURSE IN THE MANAGEMENT LITERATURE. BASE, 9 Augusti.

Henriette, E., Feki, M. \& Boughzala, I., 2015. The Shape of Digital Transformation: A Systematic Literature Review, United State of America: BASE.

Jacobi, R. \& Brenner, E., 2017. How Large Corporations Survive Digitalization . In: C. Linnhoff-Popien, R. Schneider \& M. Zaddach, eds. Digital Marketplaces Unleashed. München : Springer.

Kane, G. C. et al., 2015. Strategy, not technology, drives digital transformation. MIT Sloan Management Review and Deloitte University Press.

Keeley, L., 2013. Ten Types Of Innovation. The Discipline Of Building Breakthroughs. s.l.:Wiley.

Kääriäinen, J., Parviainen, P., Teppola, S. \& Tihinen, M., 2017. Tackling the digitalization challenge: how to benefit from digitalization in practice. 5(1), pp. 63-77. 
Manso, G., 2017. Creating Incentives for Innovation. California Management Review , 60(1), pp. 18-32.

Nagji, B, \& Tuff, G 2012, Managing Your Innovation Portfolio, Harvard Business Review, 90, 5, pp. 66-74, Business Source Premier, EBSCOhost, viewed 18 May 2018.

Nilsson, S., 2015. Making innovation everyone's business, Stockholm: s.n.

Rentzhog, O., 1998. Processorientering - En grund för morgondagens organisationer. 1 ed. Lund: Studentlitteratur AB.

Schwertner, K., 2017. DIGITAL TRANSFORMATION OF BUSINESS. Trakia Journal of Sciences, 15(1), pp. 388-393.

Solis, B., 2014. Digital Transformation And The Race Against Digital Darwinism. [Online] Available at: http://www.briansolis.com/2014/09/digital-transformation-race-digitaldarwinism/

[Accessed 14 March 2018].

Stolterman, E. \& Fors, A. C., 2004. Information technology and the good life. Information System Research, pp. 687-692.

Varis, M. \& Littunen, H., 2010. Types of innovation, sources of information and performance in entrepreneurial SMEs. European Journal of Innovation Management, , 13(2), pp. 128-154. 